\title{
Human T-cell leukemia virus type 2 Tax protein induces interleukin 2-independent growth in a T-cell line Rie Kondo ${ }^{\dagger 1,2}$, Masaya Higuchi ${ }^{\dagger 1}$, Masahiko Takahashi ${ }^{1}$, Masayasu Oie ${ }^{1}$, Yuetsu Tanaka ${ }^{3}$, Fumitake Gejyo ${ }^{2}$ and Masahiro Fujii*1
}

Address: ${ }^{1}$ Division of Virology, Niigata University Graduate School of Medical and Dental Sciences, 1-757 Asahimachi-Dori, Niigata 951-8510, Japan, ${ }^{2}$ Division of Clinical Nephrology and Rheumatology, Niigata University Graduate School of Medical and Dental Sciences, 1-757 Asahimachi-Dori, Niigata 951-8510, Japan and ${ }^{3}$ Department of Immunology, Graduate School and Faculty of Medicine, University of the Ryukyus, Uehara 207, Nishihara-cho, Nakagami-gun, Okinawa 903-0215, Japan

Email: Rie Kondo - rierie-j@d6.dion.ne.jp; Masaya Higuchi - mhiguchi@med.niigata-u.ac.jp; Masahiko Takahashi - masahiko@med.niigatau.ac.jp; Masayasu Oie - moie@med.niigata-u.ac.jp; Yuetsu Tanaka - yuetsu@s4.dion.ne.jp; Fumitake Gejyo - gejyo@med.niigata-u.ac.jp; Masahiro Fujii* - fujiimas@med.niigata-u.ac.jp

* Corresponding author †Equal contributors

Published: 02 December 2006

Retrovirology 2006, 3:88 doi:10.1186/1742-4690-3-88

This article is available from: http://www.retrovirology.com/content/3/l/88

(C) 2006 Kondo et al; licensee BioMed Central Ltd.

This is an Open Access article distributed under the terms of the Creative Commons Attribution License (http://creativecommons.org/licenses/by/2.0), which permits unrestricted use, distribution, and reproduction in any medium, provided the original work is properly cited.

\begin{abstract}
Background: While human T-cell leukemia virus type I (HTLV-I) is a causative agent of adult Tcell leukemia, HTLV type 2 (HTLV-2) is not associated with this malignancy. Accumulating evidence suggests that Tax, a transforming protein of HTLV-I or HTLV-2, plays a crucial role in the distinctive pathogenesis of these two infections. We herein examined whether Tax 2 by itself has a growth promoting activity in a mouse T-cell line CTLL-2, and compared the activity with that of Taxl.

Results: We found that Tax2 converts the cell growth of CTLL-2 from an interleukin(IL)-2dependent growth into an independent one. Cyclosporine $A$, an inhibitor of transcription factor NFAT, inhibited the growth of two out of four Tax2-transformed CTLL-2 cells, but it had little effect on two Tax I-transformed cells. While the HTLV-2-transformed human T-cell lines produce a significant amount of IL-2, Tax2-transformed CTLL-2 cells only produced a minimal amount of IL2. These results thus suggest that NFAT-inducible gene(s) other than IL-2 play a role in the cell growth of Tax2-transformed CTLL-2 cells.

Conclusion: These results show that HTLV-2 Tax2 by itself has a growth promoting activity toward a T-cell line CTLL-2, and the CTLL-2 assay used in this study may therefore be a useful tool for comparing the activity of Tax 2 with that of TaxI in T-cells, thereby elucidating the mechanism of HTLV-I specific leukemogenesis.
\end{abstract}

\section{Findings}

Human T-cell leukemia virus type 1 (HTLV-1) and HTLV type 2 (HTLV-2) are a family of retroviruses, which share around a $70 \%$ nucleotide identity and similar biological properties [1-6]. For instance, both HTLV-1 and HTLV-2 can efficiently transform primary human T-cells in vitro and establish a life-long persistent infection in humans [7-9]. The clinical outcomes of these two infections are, however, significantly distinctive. While HTLV-1 is etiologically associated with adult T-cell leukemia (ATL), 
HTLV-2 is associated with only a few cases of variant hairy cell leukemia [5,10-12].

HTLV-1 and HTLV-2 encode a transforming protein Tax1 and Tax2, respectively, which are essential for the transformation of primary human T-cells in vitro [13-16]. Accumulating evidence suggests that Tax1 is a factor responsible for the high-oncogenic activity of HTLV-1 relative to HTLV-2 [4,5]. Tax1 and Tax2 have more than 75 $\%$ amino acid identities, and they also exhibit strikingly similar functions in infected cells $[17,18]$. For instance, Tax 1 and Tax2 induce the expression of a number of cellular genes through several transcription factor binding sites, such as NF- $\mathrm{BB}, \mathrm{CREB} / \mathrm{ATF}$, SRF, and AP-1 [4,19-25]. These Tax-inducible cellular genes play a critical role in the persistent infection in host T-cells, including the transformation of human T-cells $[24,25]$, but they alone can not explain the pathogenic differences between HTLV-1 and HTLV-2, since the potencies of these functions are equivalent. On the other hand, recent results identified several differences between Tax 1 and Tax 2 , which are likely to be factors that are responsible for the pathogenic difference of two infections [4,5,26-35]. Therefore, a comparative analysis of Tax 1 and Tax 2 is a promising approach to identify a key process responsible for HTLV-1 specific leukemogenesis.

We previously showed that Tax 1 transforms a mouse Tcell line CTLL-2 from an interleukin(IL)-2-dependent growth to an IL-2-independent one, whereas Tax2 can not do so $[32,36]$. We herein reexamined the transforming activity of Tax 2 in CTLL-2 using a lentivirus vector for the transduction of the tax gene which is much more efficient than the electroporation method used in a previous experiment. Lentiviruses encoding Tax 1 or Tax 2 were produced in 293T cells, and these viruses were then infected to CTLL-2 cells in a medium containing IL-2. At 48 hours after infection, the infected cells were cultured without IL2 in a 96 well plate. Four weeks later, the number of wells containing outgrowing cells was counted by light microscopy. Unlike the previous study, Tax 2 transduced with a lentivirus induced the IL-2-independent growth of CTLL2 cells (Figure 1). A Western blotting analysis using Tax1 and Tax2 antibodies showed that all four Tax2-transformed cell lines expressed Tax 2 protein but not Tax 1 (Figure 2), thus confirming that the tax2-virus induced the transformation. Like Tax1, these Tax2-transformed CTLL2 cells continuously grow in the absence of IL- 2 for at least three months (data not shown). These results showed that Tax2 therefore induced the IL-2-independent growth of CTLL-2 cells.

We previously showed that Tax2 activates IL-2 transcription through the transcription factor NFAT, and such produced IL-2 in some HTLV-2-transformed T-cell lines stimulates their cell growth [37]. To examine whether NFAT plays a role in the Tax2-mediated IL-2-independent growth of CTLL-2, we cultured Tax2-transformed cells with cyclosporine A (CsA), a specific inhibitor of NFAT pathway (Figure 3). Two out of four Tax2-transformed cells showed reduced cell growth in the presence of CsA, while the other two showed little response to CsA treatment. On the other hand, parental CTLL-2 and two Tax1transformed cells did not show CsA-mediated growth inhibition. These results show that the activation of NFAT by Tax 2 stimulates the cell growth of some Tax2-transformed cells, but not Tax1-transformed ones. A real-time polymerase chain reaction with IL-2-specific primers showed that Tax2-transformed CTLL-2 cells minimally expressed IL-2 mRNA, whereas EL-4 T-cell line treated with phorbol myristate acetate and ionomycin produced a significant amount of IL-2 mRNA (Figure 4). We consistently detected IL-2 protein in the culture supernatant of the EL-4 cells treated with the same mitogens, but not those of the Tax2-transformed cell lines (data not shown). These results suggest that NFAT-inducible gene(s) other than IL-2 are thus involved in the Tax2-mediated growth promotion of CTLL-2 cells.

Tax2 has been shown to be essential for HTLV-2-mediated transformation of human T-cells [15]. It, however, remains to be elucidated whether Tax2 by itself has a growth promoting activity toward T-cells like Tax1 [36]. We herein showed that Tax 2 can reproducibly convert a mouse T-cell line from an IL-2-dependent growth into an independent one. These results demonstrate that Tax 2 by itself without any other viral proteins has a growth promoting activity in T-cells, thus suggesting that this growth promoting activity of Tax2 contributes to HTLV-2-mediated T-cell transformation. Since at least two functions, apoptosis inhibition and cell cycle promotion are both required for CTLL-2 to grow in the absence of IL-2, Tax2 can therefore replace these two functions in CTLL-2.

CsA inhibited the growth of two out of four Tax2-transformed CTLL-2 cells (Figure 3), indicating that NFATinducible genes are involved in IL-2-independent growth of these Tax2-transformed cells. These results are consistent with the previous results that CsA inhibited cell growth of some but not all HTLV-2-transformed human T-cell lines [37]. There are at least two explanations for the distinct responses of the Tax2-transformed cells to CsA. Tax2 may have two distinctive activities to induce IL-2independent growth of CTLL-2 cells. Alternatively, some parental CTLL-2 cells may have genetic or epigenetic change(s) conferring resistance to CsA in Tax2-transformed CTLL-2 cells. In contrast to Tax2, the cell growth of Tax1-transformed cells was little affected by CsA. This finding is also consistent with the result that Tax 1 mini- 


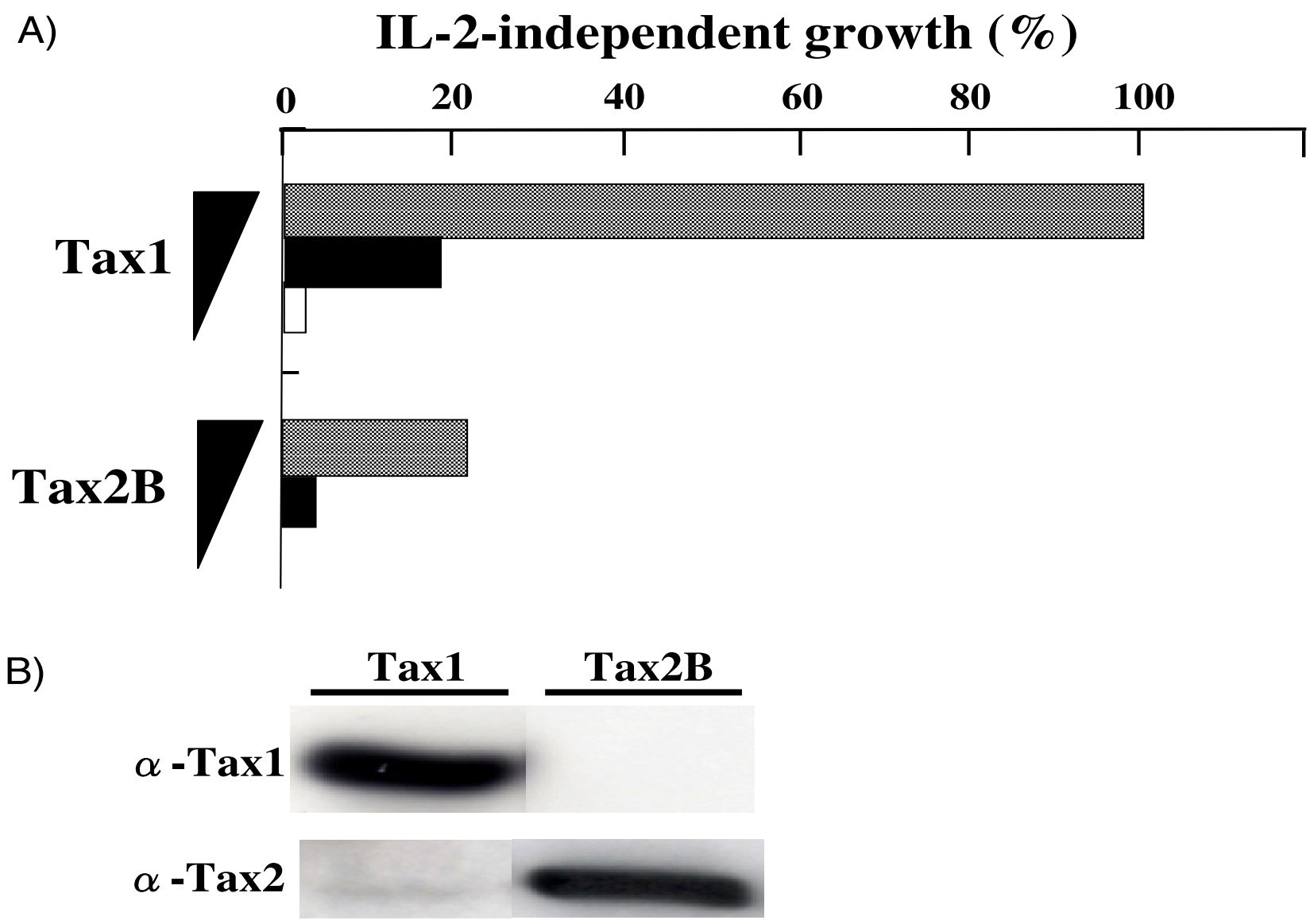

\section{Figure I}

Tax2 induces the IL-2-independent growth of CTLL-2 cells. (A) tax I and tax $2 B$ cDNAs were cloned into the lentivirus vector CSIIEF-RfA which has an elongation factor gene promoter for protein expression in mammalian cells. Lentiviruses encoding TaxI and Tax2B were produced by the three plasmid cotransfection method in 293T cells derived from an embryo kidney. These lentiviruses were transduced to CTLL-2 cells $\left(4 \times 10^{5}\right)$ in a final volume of $2.0 \mathrm{ml}$ RPMII 640 containing 10\% fetal bovine serum (RPMI/I0\%FBS), $8 \mu \mathrm{g} / \mathrm{ml}$ polybrene (Sigma) and I nM recombinant human IL-2 (Takeda). At 48 hours after infection, the infected cells were washed twice with phosphate-buffered saline (PBS), and the serially diluted cells (330/well, 1000/well, 10000/well) were cultured in 96 well plate containing RPMI/I0\%FBS without IL-2. Four weeks later, the number of wells containing outgrowing cells was counted by light microscopy. IL-2-independent growth (\%) was calculated as a ratio of the number of positive wells out of 96 wells. (B) Tax2 proteins in transiently lentivirus-infected CTLL-2 cells were undetectable (data not shown). Therefore, a human T-cell line Jurkat was infected with the lentiviruses encoding TaxI or Tax2, and $48 \mathrm{hr}$ after the infection, the amount of Tax proteins in Jurkat was measured by a Western blotting analysis. The Western blotting assay was carried out as previously described [37]. The antibodies used were antiTaxI monoclonal antibody (Taxy7) [38] and anti-Tax2B polyclonal antiserum, kindly provided by Dr. W.W. Hall (University College Dublin) [39],. 


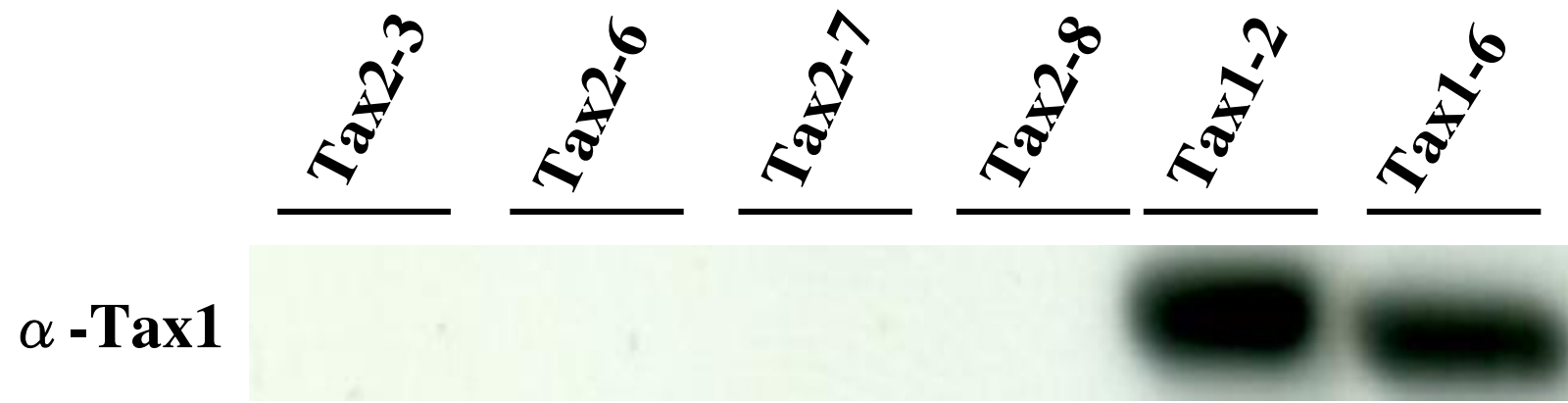

$$
\alpha-\operatorname{Tax} 2
$$

Figure 2

Expression of Tax protein in transformed cells. Cell lysates were prepared from the indicated cells, and the amounts of Tax proteins were measured by a Western blotting analysis with either anti-TaxI or anti-Tax 2 antibodies as described in Figure I [37].

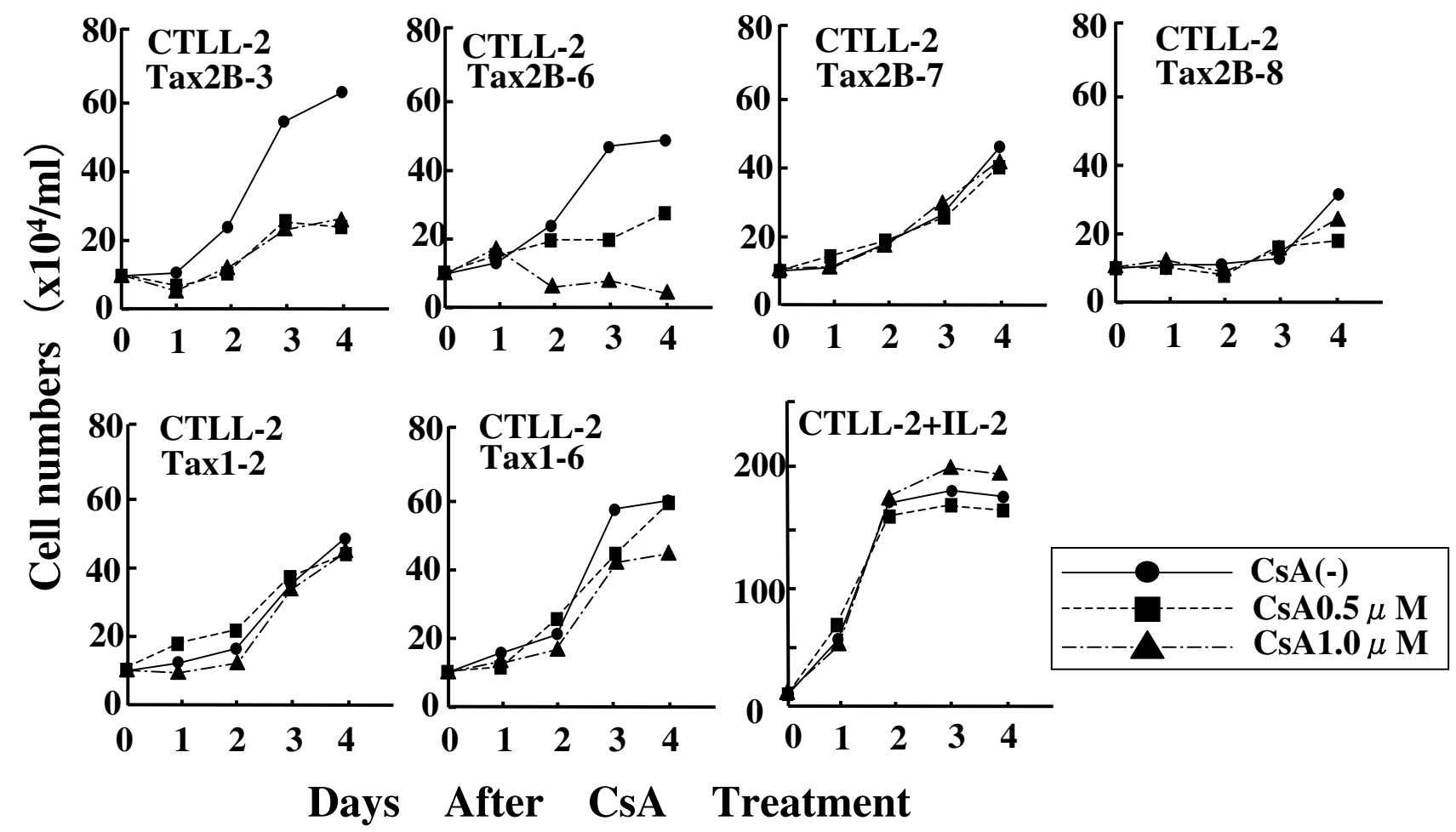

Figure 3

Growth inhibition of Tax2-transformed cells by cyclosporine A. IL-2-independent CTLL-2 cells stably expressing TaxI or Tax2B were seeded at $2 \times 10^{5}$ cells/well on a 48-well plate and cultured in the presence of either $0.5 \mu \mathrm{M}$ or I.0 $\mu \mathrm{M}$ of cyclosporine (Sigma). After culturing for the indicated days, viable cell numbers were counted by a trypan blue dye exclusion method using light microscopy. 


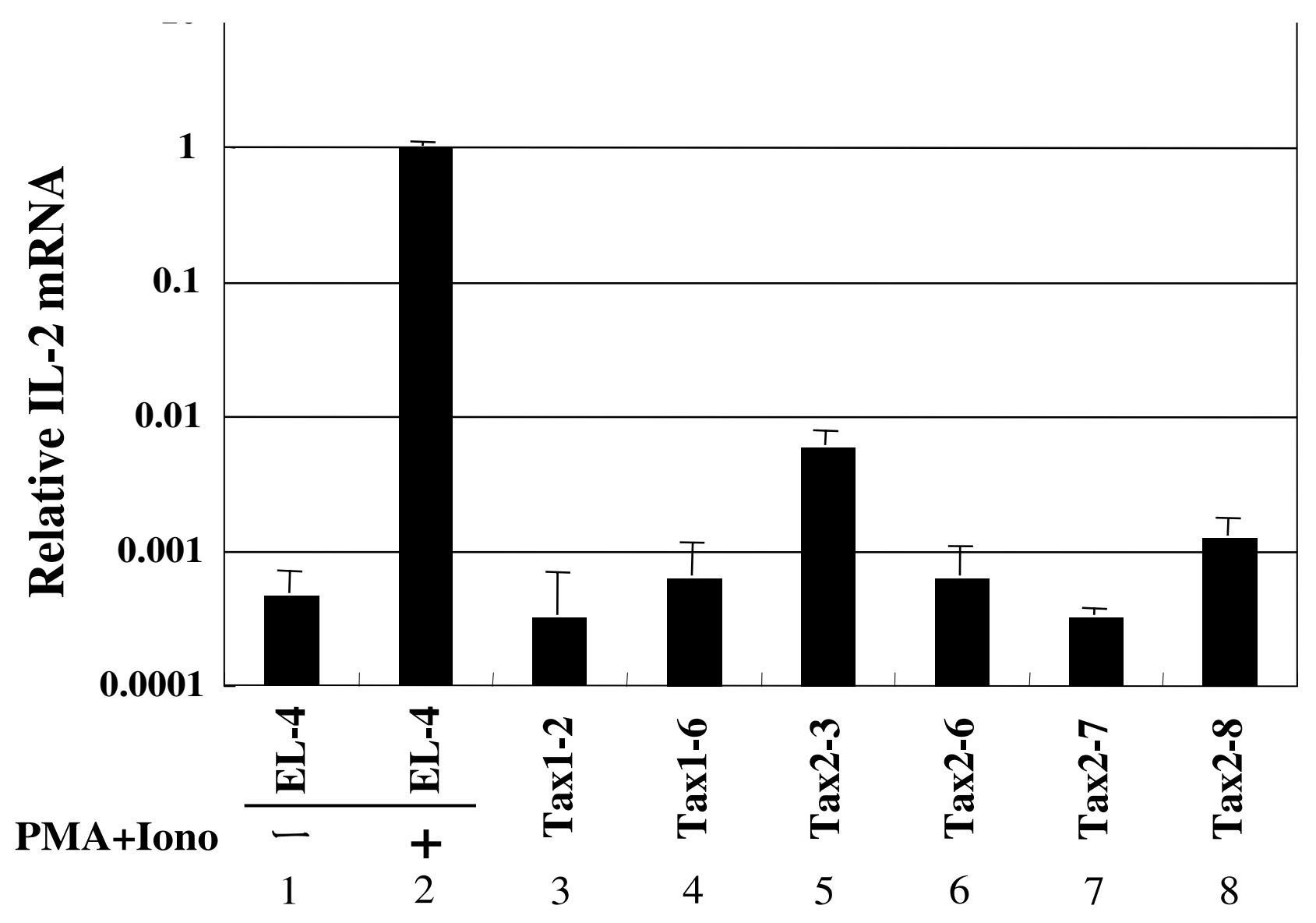

Figure 4

Minimum expression of IL-2 mRNA in Tax2-transformed cells. Total RNA was isolated from indicated Tax-transformed CTLL-2 cells (lanes 3-8), or EL-4 T-cell line treated with (lane 2) or without (lane I) $20 \mu \mathrm{g} / \mathrm{ml}$ phorbol myristate acetate and I $\mu \mathrm{M}$ ionomycin for 5 hours using RNAiso reagent, according to the manufacturer's instructions (Takara, Kyoto, Japan), and then total RNA (500 ng) was reverse transcribed using ExScript RT reagent kit (Takara). To quantify the amount of IL-2 RNA, a real-time polymerase chain reaction (PCR), based on SYBR green fluorescence, was performed using SYBR Premix Ex Taq polymerase and Takara real-time Thermal Cycler Dice (Takara). The following primers were used to specifically amplify respective genes: mouse IL-2 gene, 5'-GGAGCAGCTGTTGATGGACCTAC-3' and 5'-AATCCAGAACATGCCGCAGAG-3', mouse glyceraldehyde-3-phosphate dehydrogenase gene used as a control, 5'-TGTGTCCGTCGTGGATCTGA-3' and 5'-TTGCTGTTGAAGTCGCAGGAG-3'.

mally activates NFAT, and thus CsA can not inhibit the cell growth of any HTLV-1-transformed T-cell lines [37].

Unlike the HTLV-2-transformed human T-cell lines sensitive to CsA-mediated growth inhibition, Tax2-transformed CsA-sensitive cells expressed a small amount of IL2 mRNA (Figure 4). Since there are several NFAT inducible cytokines which promote T-cell growth, such as IL-4 and IL-21, these results indicated that the NFAT-inducible gene(s) other than IL-2 positively regulate the cell growth of the Tax2-transformed cells, thus suggesting that HTLV2-transformed human T-cells may also utilize multiple
NFAT-inducible T-cell growth promoting factors for their growth.

Accumulating evidence suggests that Tax plays a crucial role in the distinctive pathogenesis between HTLV-1 and HTLV-2 [4,5,26,28,29,32,34]. Therefore, further comparative studies of the Tax 1 and Tax 2 functions in T-cells are expected to advance our understanding of HTLV-1 leukemogenesis. The CTLL-2 assay used in this study is therefore considered to be a useful tool for examining the functions of Tax 2 and Tax 1 in T-cells, thereby elucidating the mechanism of HTLV-1 specific leukemogenesis. 


\section{Competing interests}

The author(s) declare that they have no competing interests.

\section{Authors' contributions}

RK, MH, MT, LX, and YT carried out the establishing the cell lines and the functional analysis of the cell lines. MO, FG, and MF participated in the experimental design, data interpretation, and the writing of the manuscript.

\section{Acknowledgements}

We thank Dr. Hiroyuki Miyoshi at RIKEN Tsukuba Institute and Dr. William H. Hall for the CSII-EF-RfA plasmid and anti-Tax2 antibody, respectively. We also thank the Takeda Pharmaceutical Company for providing recombinant human IL-2. We would like to express our gratituded to Chika Yamamoto for her excellent technical assistance. This work was supported in part by a Grant-in-Aid for Scientific Research on Priority Areas and for Scientific Research (C) of Japan.

\section{References}

I. Seiki M, Hattori S, Hirayama Y, Yoshida M: Human adult T-cell leukemia virus: complete nucleotide sequence of the provirus genome integrated in leukemia cell DNA. Proc Natl Acad Sci USA 1983, 80:36|8-3622.

2. Chen IS, McLaughlin J, Gasson JC, Clark SC, Golde DW: Molecular characterization of genome of a novel human T-cell leukaemia virus. Nature 1983, 305:502-505

3. Azran I, Schavinsky-Khrapunsky Y, Aboud M: Role of Tax protein in human T-cell leukemia virus type-I leukemogenicity. Retrovirology 2004, I:20.

4. Hall WW, Fujii M: Deregulation of cell-signaling pathways in HTLV-I infection. Oncogene 2005, 24:5965-5975.

5. Feuer G, Green PL: Comparative biology of human T-cell lymphotropic virus type I (HTLV-I) and HTLV-2. Oncogene 2005 , 24:5996-6004.

6. Matsuoka M: Human T-cell leukemia virus type I (HTLV-I) infection and the onset of adult T-cell leukemia (ATL). Retrovirology 2005, 2:27.

7. Miyoshi I, Kubonishi I, Yoshimoto S, Akagi T, Ohtsuki Y, Shiraishi Y, Nagata $K$, Hinuma $Y$ : Type $C$ virus particles in a cord $T$-cell line derived by co-cultivating normal human cord leukocytes and human leukaemic T cells. Nature |98I, 294:770-77|.

8. Yamamoto N, Okada M, Koyanagi Y, Kannagi M, Hinuma Y: Transformation of human leukocytes by cocultivation with an adult $\mathbf{T}$ cell leukemia virus producer cell line. Science 1982, 217:737-739.

9. Chen IS, Quan SG, Golde DW: Human T-cell leukemia virus type II transforms normal human lymphocytes. Proc Natl Acad Sci USA 1983, 80:7006-7009.

10. Uchiyama T, Yodoi J, Sagawa K, Takatsuki K, Uchino H: Adult T-cell leukemia: clinical and hematologic features of 16 cases. Blood 1977, 50:48|-492.

II. Takatsuki K: Discovery of adult T-cell leukemia. Retrovirology 2005, 2:16

12. Gallo RC: The discovery of the first human retrovirus: HTLVI and HTLV-2. Retrovirology 2005, 2:17.

13. Grassmann R, Berchtold S, Radant I, Alt M, Fleckenstein B, Sodroski JG, Haseltine WA, Ramstedt U: Role of human T-cell leukemia virus type $I \mathbf{X}$ region proteins in immortalization of primary human lymphocytes in culture. J Virol 1992, 66:4570-4575.

14. Akagi T, Shimotohno K: Proliferative response of TaxI-transduced primary human T cells to anti-CD3 antibody stimulation by an interleukin-2-independent pathway. J Virol 1993, 67: $1211-1217$.

15. Ross TM, Pettiford SM, Green PL: The tax gene of human T-cell leukemia virus type 2 is essential for transformation of human T lymphocytes. J Virol 1996, 70:5194-5202.

16. Robek MD, Ratner L: Immortalization of CD4(+) and CD8(+) T lymphocytes by human $T$-cell leukemia virus type I Tax mutants expressed in a functional molecular clone. I Virol 1999, 73:4856-4865.

17. Slamon DJ, Shimotohno K, Cline MJ, Golde DW, Chen IS: Identification of the putative transforming protein of the human $\mathrm{T}$. cell leukemia viruses HTLV-I and HTLV-II. Science 1984, 226:6I-65.

18. Seiki M, Inoue J, Takeda T, Yoshida M: Direct evidence that p40x of human T-cell leukemia virus type $I$ is a trans-acting transcriptional activator. Embo J 1986, 5:56|-565.

19. Cross SL, Feinberg MB, Wolf JB, Holbrook NJ, Wong-Staal F, Leonard WJ: Regulation of the human interleukin-2 receptor alpha chain promoter: activation of a nonfunctional promoter by the transactivator gene of HTLV-I. Cell 1987, 49:47-56.

20. Maruyama M, Shibuya $H$, Harada $H$, Hatakeyama M, Seiki M, Fujita $T$, Inoue J, Yoshida M, Taniguchi T: Evidence for aberrant activation of the interleukin-2 autocrine loop by HTLV-I-encoded p40x and T3/Ti complex triggering. Cell I 987, 48:343-350.

21. Zhao LJ, Giam CZ: Human T-cell lymphotropic virus type (HTLV-I) transcriptional activator, Tax, enhances CREB binding to HTLV-I 2 I-base-pair repeats by protein-protein interaction. Proc Natl Acad Sci USA 1992, 89:7070-7074.

22. Fujii M, Tsuchiya H, Chuhjo T, Akizawa T, Seiki M: Interaction of HTLV-I Tax I with p67SRF causes the aberrant induction of cellular immediate early genes through CArG boxes. Genes Dev 1992, 6:2066-2076.

23. Iwai K, Mori N, Oie M, Yamamoto N, Fujii M: Human T-cell leukemia virus type I tax protein activates transcription through AP-I site by inducing DNA binding activity in T cells. Virology 200I, 279:38-46

24. Sun SC, Yamaoka S: Activation of NF-kappaB by HTLV-I and implications for cell transformation. Oncogene 2005, 24:5952-5964.

25. Grassmann R, Aboud M, Jeang KT: Molecular mechanisms of cellular transformation by HTLV-I Tax. Oncogene 2005, 24:5976-5985.

26. Semmes OJ, Majone F, Cantemir C, Turchetto L, Hjelle B, Jeang KT: HTLV-I and HTLV-II Tax: differences in induction of micronuclei in cells and transcriptional activation of viral LTRs. Virology 1996, 21 7:373-379.

27. Tanaka Y, Hayashi M, Takagi S, Yoshie O: Differential transactivation of the intercellular adhesion molecule I gene promoter by TaxI and Tax 2 of human T-cell leukemia viruses. J Virol 1996, 70:8508-8517.

28. Endo K, Hirata A, Iwai K, Sakurai M, Fukushi M, Oie M, Higuchi M, Hall WW, Gejyo F, Fujii M: Human T-cell leukemia virus type 2 (HTLV-2) Tax protein transforms a rat fibroblast cell line but less efficiently than HTLV-I Tax. I Virol 2002, 76:2648-2653.

29. Hirata A, Higuchi M, Niinuma A, Ohashi M, Fukushi M, Oie M, Akiyama T, Tanaka Y, Gejyo F, Fujii M: PDZ domain-binding motif of human T-cell leukemia virus type I Tax oncoprotein augments the transforming activity in a rat fibroblast cell line. Virology 2004, 31 18:327-336.

30. Meertens L, Chevalier S, Weil R, Gessain A, Mahieux R: A I 0-amino acid domain within human T-cell leukemia virus type $I$ and type 2 tax protein sequences is responsible for their divergent subcellular distribution. I Biol Chem 2004, 279:43307-43320.

31. Sieburg M, Tripp A, Ma JW, Feuer G: Human T-cell leukemia virus type I (HTLV-I) and HTLV-2 tax oncoproteins modulate cell cycle progression and apoptosis. J Virol 2004, 78: 10399-10409.

32. Tsubata C, Higuchi M, Takahashi M, Oie M, Tanaka Y, Gejyo F, Fujii M: PDZ domain-binding motif of human T-cell leukemia virus type I Tax oncoprotein is essential for the interleukin 2 independent growth induction of a T-cell line. Retrovirology 2005, 2:46.

33. Tripp A, Banerjee P, Sieburg M, Planelles V, Li F, Feuer G: Induction of cell cycle arrest by human T-cell lymphotropic virus type I Tax in hematopoietic progenitor (CD34+) cells: modulation of p2lcipl/wafl and p27kipl expression. J Virol 2005, 79: $14069-14078$

34. Xie L, Yamamoto B, Haoudi A, Semmes OJ, Green PL: PDZ binding motif of HTLV-I Tax promotes virus-mediated T-cell proliferation in vitro and persistence in vivo. Blood 2006, 107:1980-1988 
35. Sheehy N, Lillis L, Watters K, Lewis M, Gautier V, Hall W: Functional analysis of human $T$ lymphotropic virus type 2 Tax proteins. Retrovirology 2006, 3:20.

36. Iwanaga $Y$, Tsukahara T, Ohashi T, Tanaka Y, Arai M, Nakamura M, Ohtani K, Koya Y, Kannagi M, Yamamoto N, Fujii M: Human T-cell leukemia virus type I tax protein abrogates interleukin-2 dependence in a mouse T-cell line. J Virol 1999, 73:|27|-| 277.

37. Niinuma A, Higuchi M, Takahashi M, Oie M, Tanaka Y, Gejyo F, Tanaka N, Sugamura K, Xie L, Green PL, Fujii M: Aberrant activation of the interleukin-2 autocrine loop through the nuclear factor of activated $\mathbf{T}$ cells by nonleukemogenic human T-cell leukemia virus type 2 but not by leukemogenic type I virus. J Virol 2005, 79: I I925-I I 934.

38. Tanaka $Y$, Yoshida A, Tozawa H, Shida H, Nyunoya H, Shimotohno K: Production of a recombinant human T-cell leukemia virus type-I trans-activator $(\operatorname{tax} I)$ antigen and its utilization for generation of monoclonal antibodies against various epitopes on the tax I antigen. Int J Cancer I99I, 48:623-630.

39. Lewis MJ, Novoa P, Ishak R, Ishak M, Salemi M, Vandamme AM, Kaplan $\mathrm{MH}$, Hall WW: Isolation, cloning, and complete nucleotide sequence of a phenotypically distinct Brazilian isolate of human T-lymphotropic virus type II (HTLV-II). Virology 2000, 27I: | $42-154$.

Publish with Bio Med Central and every scientist can read your work free of charge

"BioMed Central will be the most significant development for disseminating the results of biomedical research in our lifetime. "

Sir Paul Nurse, Cancer Research UK

Your research papers will be:

- available free of charge to the entire biomedical community

- peer reviewed and published immediately upon acceptance

- cited in PubMed and archived on PubMed Central

- yours - you keep the copyright 